\title{
Motivational Basis for Compensation Strategies in a Library Environment
}

\section{Shmuel Sever and Fred Westcott}

In the past twenty years two major schools of thought on motivation for performance in the work environment have arisen. Each has been extensively tested and applied with success in a wide variety of industries. These theories are summarized and the literature reviewed, with attention paid to the implications of the theories for library management. Although the theories of valence-instrumentality-expectancy and reinforcement derived from different sources, what each implies for library management is remarkably similar.

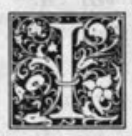

$\mathrm{n}$ the last two decades an increasing portion of business school management instruction has been devoted to theories of motivation. Yet, the literature in library journals contains little reference to the two modern theories dominating current motivational practices. Even recent library management texts reflect the old work of Maslow, Drucker, and Likert, rather than the theories of expectancy and reinforcement that predominate today.

The objective of this article is to review the two dominant motivational theories ${ }^{1}$ in use, and to supply an annotated bibliography of readings which would allow practicing library management to easily follow up on aspects of interest.

First, it is useful to consider the question of why library management should be concerned about motivating professional staff. Staff motivation can be time and effort consuming. After all, is not selfmotivation a mark of professionalism?

The greatest resource of any library is a qualified, motivated staff. The desire to work with capable people possessing high morale and who are exciting to work with is common at all levels. Not surprisingly, nearly all studies of motivation and job related behavior reflect these common feelings. By organizing these desires into the- ories capable of being tested, motivational theorists produce useful insights into problems of library management. Current theories recognize the complexity of behavior, and point out that any simplified, how-to approach is more likely to negatively motivate than positively motivate.

Aside from the degrees of selfmotivation in professionals, library management cannot view every new employee as a fully developed team member, even if they have experience from another library. Various degrees of personal and professional growth are necessary in order to bring each individual from the first entry job to full participation. This growth requires training, study, and evaluation by peers, employers, and oneself, both publicly and privately. The success of this process is absolutely vital to the success of the library, and therefore, of concern to library management. Management controls many of the elements in the environment which effect its rate and direction of growth. It is one of management's responsibilities to design a system of rewards which encourages the type of growth best suited to the library. Expectancy theories and reinforcement theories have a common concern for the needs of the individual, the effect of the environment at the workplace, and the clarity of communica-

Shmuel Sever is director of the library and chairman of library studies, University of Haifa, Israel. Fred Westcott is research support staff, Indiana University Cyclotron Facility, Bloomington, Indiana. 
tion between the manager and those who work with him.

Both the library as an organization, and individual librarians at all staff levels, are presumed to have needs which dictate their presence and their actions. The library needs to have its continued existence insured by fulfilling society's needs related to informal education, information storage and retrieval, etc. To identify these needs, the library surveys users, investigates community and funding agencies, and makes other attempts to gain information. Individuals working at the library also have needs which underlie their behavior. They seek to identify and satisfy these needs by communication with management and peers. Their behavior relates to this communication in much the same way as library planning relates to the communication of purpose and goals from society. Early motivational theories focused on identification of these needs with little resultant reduction of theory to practice. Recent research in psychology has identified a variety of specific needs empirically. Although no complete theory has resulted, the following needs or motives are consistent with expectancy and reinforcement theories.

The need for affiliation (nAff) is the need to belong; to be accepted by others regardless of gain. The need for affiliation is measured on standard personality profile tests by positive attitudes toward social relationships and concern about the happiness of others. One study ${ }^{2}$ showed that high nAff scores correlate to managerial ineffectiveness unless balanced by other characteristics.

The need for power (nPow) has been studied more as a measure of managerial strengths, but is a more complex factor. In this context, nPow relates to the desire to have influence over people, to be in control. However, nPow can be focused on personal gain or on social groups. ${ }^{3}$ The former is not associated with effective management, nor are high nPow managers effective in exercising power, since they raise defensive behavior in subordinates and superiors alike. Socially focused, high nPow individuals are those who combine a desire to influence others with a concern for group goals and with helping others achieve those goals. This face of nPow is highly correlated with good management.

The need for achievement (nAch) is a yet more complex motive than nPow, as it displays several interrelated attributes. The achievement motive is defined as a need to strive for success; the desire to do something better than it has been done before. The high nAch person is one who has a tendency to think about ways to accomplish difficult or significant tasks when such tasks are not currently assigned. One study finds a relationship between high nAch scores and high job performance. A second study shows an inverse relationship between earnings and high nAch scores for Stanford University MBAs ten years after graduation. Perhaps these contradictory results can be understood by considering the three attributes of high nAch groups. First, they set their own goals rather than adopting group goals. Second, they like to win so they will set achievable goals. Third, they like to win often and receive frequent feedback on performance.

The need for competence (nComp), or adequacy in coping with life in general, has been identified, but its role in motivation of job performance has not been determined. In a working environment nComp is characterized as a neversatisfied-search for job mastery or professional growth. The importance of nComp for management is that managers can create a working environment that will help to fulfill this need. Need satisfaction can be a reward for positive performance.

The degree of need fulfillment offered by a working environment is one-half of the final motive, the need for equity. Equity can be characterized as a desire for what is thought to be fair and just treatment, for oneself and others. This is not equivalent to being treated equally. Rewarding all employees equally, without regard for their contributions to productivity or many other factors that enter into compensation decisions, would be perceived as inequitable by many participants. Equity theory has not been actively researched because of the problems involved with measuring perception on an individual basis. ${ }^{4}$ It is useful here as a 
method of thinking about the job performance relationship to need fulfillment. The basic idea of equity is that perceptions of inequity relate to job dissatisfaction. At a certain level of perceived inequity, the individual's tolerance is exceeded and the individual takes steps to relieve that tension, such as a job change. ${ }^{5}$

Valence-instrumentality-expectancy (VIE) theory, the first and most widespread theory of motivation we will discuss, is concerned with the motivational process by which a person chooses from specific behaviors to satisfy the above needs and others. With roots in the expected utility theories of economics and psychological studies dating back to the 1940 s, VIE has become the dominant theory of motivation in work environments. VIE contains two basic assumptions: first, people are free to choose their behaviors and, second, people will choose to act in a rational manner so as to maximize gains as they perceive them. The basic idea of VIE requires definition of several terms, but can be simply stated: performance is related to the desire an individual has for a set of outcomes, and the degree of confidence the individual has that the performance will result in the desired outcomes.

Outcomes refers to the rewards, or fulfillment of needs, as perceived by the individual. Valence is the preference, or desire, an individual has for a specific set of outcomes. The probability that performance will result in particular outcomes is called instrumentality. The degree of confidence the individual has in the relationship between effort and performance is termed expectancy. In some formulations of the theory, both of these probabilities are collectively termed expectancy.

Based on the assumptions of free choice and rational process, VIE provides a model for the decision process used to select a behavior pattern. When a task is assigned, VIE assumes the following mental process takes place: First, behavioral choices are identified. These choices may include effort level, time devoted to the task, priority compared with other tasks and personal activities, etc. Then, outcome for each behavior pattern is identified: e.g., monetary rewards, self-esteem, peer group reaction, and promotion possi- bilities. Then expectancy, the probability that planned effort will result in desired performance level, is calculated based on how well the task is understood, the individual's self-esteem, past experiences with similar tasks, communications received from management or others about the task, and other influences. Performance to outcome probability (instrumentality) is then estimated, based on past experience with similar performance levels, communications received from others about rewards, the degree of task and role model communication, the attractiveness of the outcomes and the expectancy calculation. The desirability (valence) of each outcome is gauged, including negative outcomes such as effect on work group relationships and outside job relationships. Finally, the probabilities are multiplied by the valence for each outcome and summed to produce a ranked list of behavior pattern choices for selection.

An attempt to follow this model on paper for even a simple behavior choice can either raise serious doubts about the theory, or impress one with the unconscious power of the mind. However, it seems that at least some of the basic tenets of the theory have been tested and hold true.

Over fifty studies have been done to test the validity of the expectancy theory approach to predicting employee behavior. Almost without exception, the studies have confirmed the predictions of the theory. As the theory predicts, the best performers in organizations tend to see a strong relationship between performing their jobs well and receiving rewards they value. In addition they have clear performance goals and feel they can perform well. ... Finally, the theory correctly predicts that beliefs about the outcomes associated with performance (expectancies) will be better predictors of performance than will feelings of job satisfaction since expectancies are the critical causes of performance and satisfaction is not. ${ }^{6}$

VIE is a method of thinking about motivation which asks managers to consider what they want from their subordinates and what the subordinates want from the organization. VIE argues for having rewards contingent upon successful performance, and stresses the need for clear, reliable communication of both the results desired by management, and the relation- 
ship of those results to rewards received by the employee. For library management the stress is on the necessity for clear communication of available rewards and the commitment to only those rewards that the manager can actually deliver. It is not reinforcing to promise a promotion, funds for a pet project, release time for a conference or similar reward, only to be unable to deliver when the employee achieves target performance.

The problem of many library management groups having today's austere budgets is that significant monetary rewards are simply not available, or require lengthy procedures for which there is no certainty of favorable outcome. We offer the following as an example of the use of rewards that can be reliably promised, even in an atmosphere more restrictive in regards to raises than American libraries. In the University of Haifa Library, as in all libraries in Israel, raises in pay are not directly under the control of library management. Entry position grades and pay are fixed, and progression in grade is not directly performance-related. Some years ago the director of the library began to experiment with customized job enrichment as an incentive. In one case, an assignment to work on a team producing an index and thesaurus to Hebrew periodicals was given as a reward. Most of this work was performed during unpaid overtime and had little budget impact. Because of the difficult nature and creative demands of the work, team members gained a great deal of recognition and professional growth which they found very rewarding. Indeed, as the work progressed and the expectancy of these rewards rose, other members of the library sought out the director to inquire how they could become similarly rewarded. As the perceived relationship between performance level and reward increased, the motivation level of the entire library staff rose, just as predicted by VIE.

It is not necessary, of course, to find an original research task as a reward, although there are many such waiting projects. In a similar case, a librarian was rewarded with support for development of an extensive collection and display of art slides. The library collection development policy did not contain an objective requiring such an extensive development of media in the art collection, however, rewarding the initiative of the librarian by providing resources, resulted in expansion in academic use of the slide collection and the other media throughout the university. Again, the knowledge of the reward and its relationship to the librarian's performance was communicated throughout the staff, and as a result, motivation levels and performances increased.

The second comprehensive model of motivation, behavior modification or reinforcement theory, has also been widely tested and verified. However, a storm of criticism $^{7.8}$ leveled at the ethics of the concept, partially because of its relationship to reflex behavior modification, has retarded its application. Many of these criticisms are unfounded. The basic concept of reinforcement theory is that human behavior selection is not cognitive, but reactive to environment, and that the incidence of desired behaviors can be markedly increased by controlling the environment and positively reinforcing desired behaviors.

Reinforcement theory is not concerned with what motivates an individual to select the desired behavior, as is the need theorist, nor is reinforcement theory concerned with the process of behavior selection as is VIE. Instead, the individual is responsible for determining his needs, perceptions of equity, desired outcome, and expectancy calculations. Reinforcement theory asks that the manager be concerned only with the observable event of the frequency with which desired behavior is repeated, and to insure that desired behavior is rewarded without fail. It is assumed that the employee will want the reward enough to repeat the behavior, provided rewards valued by the employee are selected, and the value of the reward is significant. 9,10

Reinforcement theory is concerned with voluntary behavior rather than the classical conditioning of reflex behavior. In classical conditioning, an unrelated stimulus (bell) is placed in the environment just before a stimulus (food) is introduced. In time, the behavior associated with the presence of food is exhibited whenever 
the bell is rung, even when there is no food. It is this early work, associated with reinforcement theory by its critics, that often produces negative emotional reactions.

Reinforcement theory is more closely related to learning theories, and presumes that as an individual interacts with his work environment he attempts to satisfy his needs (affiliation, power, achievement, etc.) by controlling behavior patterns. The work environment and his own internal reward system give him a choice of positive and negative rewards for each pattern of behavior chosen. The pattern producing the greatest net reward will be repeated until the reward level satisfies the person's needs. "Such a stimulus does not act as a goad; it does not elicit the response as was the case in classical conditioning of reflex behavior in the sense of forcing it to occur. It is simply an essential aspect of the occasion upon which response is made and reinforced.",11

The variety of studies and applications of reinforcement theory has resulted in the development of an extensive literature on technique, not all of which is according to theory. The use of reinforcement theory requires significant managerial effort to control spurious reinforcements and reward behavior. Managers must have a clear understanding with subordinates about which behaviors will be rewarded and which will not. Erroneous behaviors must be detected and ways of overcoming errors trained. Detection of errors and subsequent retraining must be done with awareness of the ease of extinguishing good behavioral aspects along with those which initiated the errors. For instance, failure in an endeavor connected with an employee's initiative should not be handled in a way which inhibits future initiatives. Error correction should attempt to prevent failures while retaining the rewards for initiatives. One must be careful to insure that the rewardable behavior is achievable for the individual given his current capabilities, not simply a level of performance that the more experienced or talented librarian can reach, but which is not feasible for the individual at this time. Good behavior must be recognized frequently. Rewards must be differentiated by performance levels. ${ }^{12,13}$ All employees cannot be rewarded equally, for if a clear relationship between performance and rewards is not perceived, there is little reason to believe the employee will exert extra effort to accomplish a task.

Perhaps the most important point of reinforcement theory is that it does work. The implication of this point is that either one manages the reinforcers in the work environment, or, the reinforcers get managed by accident. Either way reinforcers are present and have their effect. The choice is between controlling or not controlling; between deciding what behaviors are best for the library or living with the behaviors that develop. This is not to imply that library management can control the reinforcers in the work environment and not be aided or defeated by rewards in the individual's life outside the control of the manager.

One common use of reward systems outside the work environment is adjustment of hours to a flexible schedule, when the job allows it, even to the point of reducing some jobs to part-time status. The library at the University of Haifa used this reward for many of its employees, with favorable results. For instance, reduction to part-time for librarians in some positions led to increased productivity and permitted an expanded use of human power in reference desk service where long hours are often not productive. Flexible hours also offered rewards of increased family life for young staff members. For some, this reward was more meaningful than the career enhancement associated with more responsibility. It was made clear that this reward carried its own negative which was the incompatibility of career advancement to more responsible positions with current hours reductions. Thus, when a high performance department head who was hired under the promotion system imposed on the library by national standards, could not be rewarded by salary increases, requested the reward of hours reduction, the request was flatly denied. The possibility of cutting back both responsibility and work time may not always be available. Release time, for increased study or professional conferences in excess of the normal allotment, is a posi- 
tive reward. Encouragement for research or writing projects are strong motivating rewards for some employees, even when performed primarily on uncompensated overtime.

Several differences between VIE and reinforcement deserve to be pointed out, especially since adherents to VIE often criticize behavioralists. Reinforcement theory suggests that people react to their environment. VIE asserts that people make conscious choices based on information about future consequences. Reinforcement theory claims that present behavior is based on the results of past behavior. The difference is in what is considered most important for motivating behavior. VIE says that the employee's beliefs about the future are most important. Consequently, the factors that influence these beliefs are where the manager should look to change motivation levels. These are the factors that influence expectancy since valence (i.e., preference for a set of outcomes) is less available to managerial influence. Thus, the manager should be concerned about what others in the work group are saying about the relationship between performance and reward and about the difficulty of the task. The manager needs to hear what he is saying about these same factors and how clearly he is saying it. Reinforcement theory asserts that, if attention is given to clearly associate rewards with desired behavior, beliefs will change as past experiences are overshadowed by more recent experiences. It seems clear that both past experience and expectations influence behavior.

Although no effort to reconcile proponents of these theories has reached publication, the implications for practical managers are markedly similar. Both theories place strong emphasis on performancereward relationships. VIE may express it in terms of outcomes and valenceexpectancy, while reinforcement theorists call similar concepts rewards and reinforcement, but what it says to a manager is that a clear, consistent communication of what he wants, combined with a clearly associated reward when he gets it, will influence job performance favorably. It is important, not only that the understandings be clear and open to all employees, but also that the rewards promised by the manager are those which he has the authority to promise, and which can be given to the employee without delay.

What do these theories imply for the design of compensation strategies for a library? Both theories and their supporting studies show that the design of pay and other reward systems should be related to what the library wants to achieve in terms of job performance, and to the available tools used by library management as rewards. Raises and promotions connected with time of service are related to low motivation, low performance and poor morale. The communication of a direct, credible relationship between performance and rewards is essential to both theories. Thus, open postings of available promotions, salaries, and the basis for all rewards given are recommended. Secret pay and promotion systems should be eliminated as nonfunctional techniques. Lack of this communication reduces instrumentality in the language of VIE and impedes reinforcement in behavioral theory terms.

The design of specific jobs and roles is a second focus for both theories. Knowledge of the needs, valences, or reinforcers for the employee reveals those job enrichment items relevant to each person as rewards. By using job design in an environment that rewards desired behavior intrinsically, much of the administrative burden of using these theories is relieved. ${ }^{14}$

The importance of group structures is pointed out most strongly by expectancy theory and is an important source of the environmental reinforcers for behavior. ${ }^{15}$ Rewards structured around team or group performance are especially appropriate for a library where interaction between organizational entities is necessary. It is often easier to determine desired performance levels for a group than it is for individuals, especially when cooperative interaction is necessary to achieve a goal. One can think of the analogy of a symphony in which very talented professionals play a variety of instruments, each valuing the particular rewards unique to the instrument and to the sounds the individual musician can make, yet actualizing 
these rewards in the resultant cooperative effort directed by the conductor.

Communication of goals, desired performance levels, and rewards for achievement are key to both theories. The first level of management above task performance is the most critical communication link to the library's plans. The authority to make a commitment to specific rewards needs to be given to the first line supervision level. Control review at higher levels is necessary, but library management should be wary of any action which may lead to undermining belief in a direct connection between performance and reward.

Periodic performance analysis is supplanted in both theories with an assessment of motivational level. Since desired behaviors are specified by relating them to performance goals, and directly rewarded as goals are achieved, no useful purpose demands the annual or semiannual review. The use of such a review, if it has any relationship to determining rewards, is in violation of the principles of both theories. One method of determining motivational level is a standardized employee questionnaire $^{16}$ combined with individual interviews, but there are many ways by which this information may be acquired. The authors' favorite example of determining a librarian's motivation is that of an original cataloger, proficient in a variety of uncommon languages, and having an outstanding record of accomplishment. She stated that she was going to declare early retirement and wished not to do any cataloging during her remaining two years of service. Her motivational level was low. After some discussion it was revealed that a computer terminal used for copy cataloging had recently been installed in the cataloging department. Her status as an original cataloger with difficult material was such that the department head dared not suggest that she be trained in terminal operations as were other members of the department. Training in the use of the computer, however, restored her motivation and preserved her valuable performance and language skills for original cataloging.

Since an organization applying either theory obtains data about the value each individual places on all elements of the fringe benefit package, some of which are not budget related, it is possible to use fringe benefits as part of the reward system. In times of reduced budget, when money is not as available to use for meaningful rewards, job enrichment and customized fringes can be invaluable tools for reinforcing behavior. ${ }^{17}$

Both literature and experience indicate that these two theories of motivation have much to offer a library manager, however, none of the studies on the application of these theories were in a library environment. The library is certainly different in many ways from an industrial work environment, even a service industry. The librarian, given the pay scales endemic to libraries, probably is not motivated by money as much as other job and professional rewards. According to both theories a person of this type is likely to respond favorably to the intrinsic rewards contained in job design, customized fringe benefits, and perquisites. The library would seem to be a rich area for further research in the application of these theories.

\section{REFERENCES}

1. R. M. Steers and L. W. Porter, eds., Motivation and Work Behavior (2d ed.; New York: McGraw-Hill, 1979); T. A. Mahoney, Compensation and Reward Perspectives (Homewood, Illinois: Irwin, 1979); H. Campbell and R. D. Pritchard, "Motivation Theory," in M. D. Dunnette, ed., Handbook of Industrial and Organizational Psychology (Chicago: Rand McNally, 1976), p.63-130. The three sources listed above are comprehensive summations of current motivational theory. The first two are collections of articles by the major researchers in the field and contain summations and commentaries by the editors. The last is a lengthy summary and comprehensive bibliography. All have been heavily drawn upon for this article and are highly recommended for any collection on motivation in the job environment.

2. D. C. McClelland and D. H. Burnham, "Good Guys Make Bum Bosses," Psychology Today 9:69-73 (Dec. 1975). Recounts the relative importance of the need for power and the need for affiliation as a 
predictor of managerial effectiveness. Also cites high correlation between high need for power scores and incidence of heart disease.

3. D. C. McClelland and D. H. Burnham, "Power is the Great Motivator," Harvard Business Review 54:100-109 (Mar.-April 1970). For a more complete exposition of the relationship of power to managerial effectiveness see Power: The Inner Experience by D. C. McClelland (Boston: Irvington, 1975). From their studies the authors conclude that socially mature persons with a strong need for power make the best managers. They point out problems that individuals with a high need for achievement and a low need for power have in a managerial role.

4. M. R. Carrell and J. E. Dittrich, "Equity Theory: The Recent Literature, Methodological Considerations and New Directions," Academy of Management Review 3:202 (April 1978). Comprehensive review of equity and of recent literature in which equity has played a part in motivational studies.

5. F. Herzberg, B. Mausner and B. B. Snyderman, The Motivation to Work (New York: Wiley, 1959). No bibliography on motivation would be complete without a bow to Herzberg. Not only is his writing style and prolific output worthy of the accolade but the points in this book underlie the more proven aspects of both theories: i.e., open, clear communication of reasons for work.

6. Steers and Porter, Motivation and Work Behavior.

7. C. E. Schneier, "Behavior Modification in Management: A Review and Critique," Academy of Management Journal 17:528-48 (July 1974). Representative of the body of critical literature on reinforcement theories. Reviews much of the literature related to both VIE and reinforcement theories from a critical point of view.

8. M. R. Lepper and D. Greene, The Hidden Costs of Reward: New Perspectives on the Psychology of Human Motivation. (Hillsdale, New Jersey: Laurence Erlbaum Associates, 1978). Collection of highly critical essays on VIE and reinforcement theories using rewards. Points out areas for caution, areas where the theories are not complete or proven and gives examples of reward systems that do not perform as expected.

9. W. C. Hamner and E. P. Hamner, "Behavior Modification on the Bottom Line," Organizational Dynamics 15:2-21 (Spring 1976). Describes determinants of employee performance from viewpoint of reinforcement theory in clear language. How-to rules are given which are typical of current applications of the theories. Librarian users should realize that such rules may not apply completely to their library and staff.

10. R. A. Guzzo, "Types of Rewards, Cognitions and Work Motivation," Academy of Management Review 14:75-86 (1979). Intrinsic and extrinsic rewards are differentiated in many studies of reinforcers. Author points out that these are not independent variables and that basis for concluding one type is superior to another is inadequate.

11. B. F. Skinner, Contingencies of Reinforcement: A Theoretical Analysis (New York: Appleton-CenturyCrofts, 1969). Initial work on reinforcement theory.

12. F. P. Bordorano, "The Dilemma Created by Praise," Business Horizons 19:76-81 (Oct. 1976). Author discusses possible negative feedback that can occur when praise is used as a reinforcer. Praise is relative to the individual's self-esteem and to be effective must be in excess of what the person feels he deserves. However, too much over this trigger level and a feeling of manipulation sets in causing negative reinforcement. Moreover, excessive use of praise causes manager's opinions to be downgraded in value by employees.

13. J. R. Hackman and J. L. Shuttle, eds., Improving Life at Work: Behavior Science Approaches to Organizational Change (Santa Monica, California: Goodyear Publishing, 1977). Contains solicited chapters on aspects of the title by major researchers in the field. Chapter four by E. E. Lawler III is an overview of rewards systems primarily from a viewpoint of expectancy theory. Among aspects noted are elimination of secrecy in job promotions and wages, individualized fringe benefits and job evaluation and design.

14. E. E. Lawler, III, "The Individualized Organization: Problems and Promises," California Management Review 17:31-39 (Winter 1974). Author is recognized leader in field of motivation theory. For a more complete exposé of the author's views see Pay and Organizational Effectiveness: A Psychological View (New York: McGraw-Hill, 1971). This article discusses job design and enrichment, training and techniques for determining individual differences upon which to base individualized job design and reward structures.

15. H. Campbell, "Group Incentive Payment Schemes: The Effects of Lack of Understanding and Group Size," Occupational Psychology 26:15-21 (Jan. 1952). Schemata and analysis of group reinforcers are discussed.

16. L. W. Porter, Job Attitudes in Management, Perceived Satisfaction and Importance of Needs (Berkeley, University of California, Institute of Industrial Relations, Reprint no. 129, 1964). Contains questionnaire for determining motivational level and reinforcers.

17. Lawler, "Individualized Organization." 